\title{
Anchoring silver nanoparticles on imidazolium- based poly(ionic liquid)s with engineered nanopores as an efficient carrier for anticancer drug controlled delivery with antimicrobial effect
}

\section{Ehsan Aliakbari}

Tabriz University of Medical Sciences

\section{Reza Eghdam Zamiri}

Tabriz University of Medical Sciences

Mehri Mahdavi

Tabriz University of Medical Sciences

Vahid Yousefi ( $\square$ vahid.yousefi@chemist.com)

Tabriz University of Medical Sciences/university of maragheh https://orcid.org/0000-0002-9304-113X

\section{Research Article}

Keywords: poly (ionic liquids), mesoporous nanomaterial, silver nanoparticle, Anticancer Drug, Drug Delivery, antimicrobial

Posted Date: January 14th, 2022

DOI: https://doi.org/10.21203/rs.3.rs-1252789/v1

License: (c) (i) This work is licensed under a Creative Commons Attribution 4.0 International License. Read Full License 


\section{Abstract}

Due to the significance of drug delivery, the design of novel progressive nanomaterials for targeting drug delivery is a significant role in pharmacotherapy, as this method is supposed to reach a more exact target. One of the most distinguished materials by researchers is the poly ionic liquid (PIL), which have been used as anticancer drugs carriers and notably improve the antitumor effect and half-life. In this work, an efficient and stable nanocarrier containing silver nanoparticle, which were well distributed throughout the ionic liquid-based copolymer network (PILP-Ag), was reported for the drug delivery with antimicrobial effect. PILP was synthesized by radical silver nanoparticles was anchored into PIL voids by in-situ reduction, which enrich the adsorption capability of drug and antimicrobial effect of the nanocarrier. The synthesized nanomaterials were characterized by various techniques such as BET, TGA, SEM, TEM, AAS and FT-IR spectroscopy. The antibacterial activities of the silver-containing PIL against both S. aureus and $\mathrm{E}$. coli were studied by determination of the minimum inhibitory concentration and Minimum Bactericidal Concentration.

\section{Introduction}

Todays, one of the main methods for treatment of various cancers is chemotherapy [1]. Nevertheless, some inevitable obstacles restrict the therapeutic effects of chemotherapy, such as the toxicity of normal and healthy cells and poor circulation [2]. To overwhelm these limitations, many attempts have been fulfillment to produce targeted chemotherapeutic agents for the tumor [3-7]. Due to the significance of nanocarriers, the design and synthesis of new modified and advanced materials for drug delivery to the target have been played an important role in chemotherapy [8-10].

Amphiphilic nanopolymers have been used as nanocarriers of anticancer drugs and are one of the most versatile due to the ease of loading of target ligands, size and control structure during synthesis and selectivity of individual blocks to prepare copolymers to regulate drug loading, are one of the most versatile and powerful nanocarriers. However, the weak structure and adverse drug loading in the structure of usual amphiphilic copolymers is a primary unresolved challenge for them. Consequently, the development of new amphiphilic block copolymers is still necessary to resolve this issue [11-18].

Recently, polymeric ionic liquids (PILs) due to having smart structures in terms of charge density, glass transition temperature, molecular weight, lipophilic/hydrophilic balance, water solubility and specially mobility of the counter-ions are appropriate in the development of demonstration outstanding pharmacological activities in antitumor, antimicrobial and anti-inflammatory [19-22]. PILs are polyelectrolytes that comprise a polymeric block and IL species in monomer repeating units. Due to presence of the multi-charged cations and anions and have a wide range of selectivity of them in the PIL structure, design of the ionic liquid monomers and also numerous polymerization methods can develop and tune the properties and structures of PILs, which have excited increasing regard in expanding versatile materials as well as bio-materials [23-25]. In addition, in recent years, many researchers have introduced different and efficient antimicrobial cationic monomers and polymers with high microbial 
selectivity for antibacterial activities tested on animal cells [26-29]. Consequently, increasing attention is being paid to efficient antimicrobial cationic monomers and polymers, like pyridinium, quaternary ammonium, imidazolium, and phosphonium based nanomaterials.

Despite the widespread use of the above methods and materials, it is necessary to develop new PILbased materials as well as preparation with neither wrapped synthesis method nor accurate control strategies. Likewise, based on research on the antimicrobial effects of silver, in this work, silver nanoparticles were formed by in situ reduction method inside polymer cavities to not only increase the effect of drug adsorption and release, but also to increase the antimicrobial effect of the substance. So far, no article has been reported on the synthesis of this polymer, so certainly this polymer was synthesized for the first time and used as a drug carrier. At this point, it is believed the integrating of PILP and Ag Nps providing organic-inorganic nanocomposite that can open new viewpoint about to extending biomedical application.

In this study, we synthesized with facile method a form of mesoporous poly(ionic liquid) by radical polymerization. The synthesized nanomaterials were characterized by various techniques such as nitrogen adsorption-desorption analysis, thermal gravimetric analysis (TGA), TEM, and FT-IR spectroscopy. Besides, PILP-Ag synthesized-nanocomposite was used as an efficient nanocarrier for release of MTX with high antibacterial activity and without cytotoxicity effect with their high efficiency and high physicochemical stability of the nanostructure.

\section{Experimental}

\subsection{Chemicals and Reagents}

$\mathrm{N}$-vinyl imidazole, Divinylbenzene, Azobisisobutyronitrile, benzyl bromide, silver nitrate, ethylene glycol and all solvents were purchased from Merck Chemicals Co. and Aldrich Chemical Reagent Co. Ltd. Fourier transform infrared spectra of the synthesized nanomaterials were recorded over the range of 400$4000 \mathrm{~cm}^{-1}$ region by using a Thermo Nicolet model Nexus 870 FT-IR spectrometer.

The synthesized nanomaterial were illustrated by transmission electron microscopy (Philips EM 208S). The specific surface area was determined from the linear part of the BET plot, and the pore size distribution was calculated from the adsorption branch using the Barrett-Joyner-Halenda (BJH) method analyzer (BELMAX, Japan), and synthesized-nanocatalyst was first degassed at $80^{\circ} \mathrm{C}$ for $4 \mathrm{~h}$. Thermogravimetric analysis (TGA) was carried out using a simultaneous TG apparatus (Linseis model L81A1750 Germany). The rate of the absorbance of the drugs was measured by UV-vis spectroscopy (UV-1700 Pharma Spec, Shimadzu).

\subsection{Synthesis of ionic liquid monomer}

In a typical experiment, benzyl bromide $(2.4 \mathrm{mmol})$ was dissolved in ethyl acetate $(10 \mathrm{ml})$ in ice-bath condition, and 1-vinyl imidazole $(20 \mathrm{mmol})$ was added slowly to the above solution. The mixture was 
refluxed for a day and then was stirred $2 \mathrm{~h}$ at room temperature. Later, the reaction mixture was cooled down, the liquid was separated, and the solid residue was washed several times with ethyl acetate (20 $\mathrm{mL}$ ) and chloroform $(4 \mathrm{~mL})$ to remove the unreacted starting materials. After drying by vacuum for a day at ambient temperature, a light-yellow solid was obtained as the ionic liquid (IL) monomer ILVI-Br.

\subsection{Preparation of porous ionic liquid polymer}

In a typical synthesis, $1 \mathrm{~g}$ of Divinylbenzene, $93 \mathrm{mg}$ of ILVI-Br, and $15 \mathrm{mg}$ of AIBN were dissolved in $15 \mathrm{~mL}$ of ethyl acetate and mixed. After stirring at room temperature for $3 \mathrm{~h}$, the mixture was treated for $15 \mathrm{~h}$ at $75^{\circ} \mathrm{C}$ and then for a day at $100^{\circ} \mathrm{C}$. After cooling naturally to room temperature, the resulting mixture was filtered and washed several times consecutively with deionized methanol and water. Lastly, $1.2 \mathrm{~g}$ of dry solid porous ionic liquid polymer (PILP) was obtained after being dried at $60^{\circ} \mathrm{C}$ under vacuum for $12 \mathrm{~h}$.

\subsection{Synthesis of PILP-Ag organic-inorganic nanocomposite}

Next, $0.5 \mathrm{~g}$ of the PILP were added to $20 \mathrm{~mL}$ of water and placed in ultrasound for $1 \mathrm{~h}$ to get a uniform copolymer dispersion. Then, $150 \mathrm{mg}$ of the silver nitrate was dissolved in $5 \mathrm{ml}$ deionized water/ethylene glycol (3:1), added to the mixture mentioned above, and stirred vigorously under nitrogen atmosphere. After stirring for an hour, $100 \mathrm{ml}$ of ethylene glycol was added to mixture and was stirred under vigorously stirring and nitrogen atmosphere at $100^{\circ} \mathrm{C}$ and for $6 \mathrm{~h}$. After reduction, the mixture kept being stirred at room temperature for $1 \mathrm{~h}$, then filtered, washed several times with water $(20 \mathrm{ml})$ and methanol $(20 \mathrm{ml})$, and dried at $70^{\circ} \mathrm{C}$ for $24 \mathrm{~h}$. AAS results showed that the exact amount of silver in the structure was 0.82 $\mathrm{mmol} / \mathrm{g}$.

Finally, to load MTX, $3 \mathrm{~g}$ of PILP-Ag organic-inorganic nanocomposite was immersed in $100 \mathrm{ml}$ distilled water containing $3 \mathrm{~g}$ of the MTX and $1 \mathrm{~g}$ of potassium hydroxide with $\mathrm{pH}$ control at 9 at room temperature for $24 \mathrm{~h}$.

\subsection{Drug Release from drug-containing PILP-Ag organic- inorganic nanocomposite}

The MTX-Containing PILP-Ag organic-inorganic nanocomposite $(0.15 \mathrm{~g})$ was blended with $100 \mathrm{~mL}$ of PBS, $150 \mathrm{rpm}$ and at $37^{\circ} \mathrm{C}$ in $\mathrm{pH}$ 7.4. Then, in each series of drug release test at the specified time, $5 \mathrm{ml}$ was taken from the solution and immediately at the same time intervals; the equal amount of the fresh solution was added to the solution to keep the amount of solution constant. The removed solution was centrifuged and then released MTX from structure was measured by UV-vis at $302 \mathrm{~nm}$.

\subsection{Antibacterial assays}

To evaluate the antibacterial activity, several strains of gram-positive and gram-negative bacteria were purchased from the Iranian Biological Research Center (IBRC), including Escherichia coli 0157 PTCC 1276 and Streptococcus aureus ATCC 35668. The MIC is the lowest concentration of PILP-Ag organicinorganic nanocomposite, which inhibits the growth of bacteria after $24 \mathrm{~h}$ incubation. The MBC is the lowest concentration of PILP-Ag organic-inorganic nanocomposite required to kill bacteria after $24 \mathrm{~h}$ 
incubation. The Minimum Inhibitory test was achieved in 96-well round bottom microtiter plate using standard broth micro dilution routes while the Minimum Bactericidal Concentration test was achieved on the MHA plates. The bacterial inoculums were adjusted to the concentration of McFarland standard (106 $\mathrm{CFU} / \mathrm{mLF}$ or the MIC test, $100 \mu \mathrm{L}$ of PILP-Ag organic-inorganic nanocomposite of the stock solution (2048 $\mu \mathrm{g} / \mathrm{mL}$ ) was added and diluted with the bacterial inoculums in $100 \mu \mathrm{L}$ of Mueller-Hinton broth at $37^{\circ} \mathrm{C}$ for a day and sub-cultured in $5 \mathrm{~mL}$ of the same medium at $37^{\circ} \mathrm{C}$.

\subsection{Cytotoxicity assays}

To evaluate the cytotoxic activity of PILP-Ag organic-inorganic nanocomposite, MTT assay, a colorimetric test to evaluate the metabolic activity of cells, was used. HFF-2 Fibroblast Cells were purchased from Pasteur Institute of Iran and $0.1 \times 10^{4}$ cells were added to each well containing DMEM culture medium (plus $10 \%$ FBS and concentrations of $0.005,0.001,0.05$, and $0.01 \mathrm{~g}$ of synthetic nanostructures). All concentrations were repeated three times. After 48 hours of incubation, the old culture medium was replaced with a new medium containing MTT solution $(5 \mathrm{mg} / \mathrm{ml})$, and the cells were incubated again for 4 hours at $37^{\circ} \mathrm{C}$. Formazan crystals were visible by adding DMSO. Finally, the absorbance was measured at $570 \mathrm{~nm}$ by the spectra reader (Biotek, EL $\times 800$ ). Positive control (cells without nanoparticles) and negative control (DMSO treated cells) were used. Data were analyzed using one-way ANOVA by GraphPad prism and were expressed as means \pm S.E.M. $p$-value $<0.05$ was considered statistically significant.

\section{Results And Discussion}

In order to improve access to the functional locations of PILs, the structure was designed and controlled during the synthesis process so that the structure became porous without the use of a template to have the best form for drug loading and the availability of nanoparticles. Fig. 1 demonstrates the synthetic procedure for PILP-Ag organic-inorganic nanocomposite. In the synthesis of PILP-Ag organic-inorganic nanocomposite, after reaction of benzyl bromide with 1-vinyl imidazole, DVB as a cross-linker, and AIBN as a radical initiator, were added to mentioned mixture and stirred for completely reaction with ILVI-Br. Ethylene glycol was used as green and inexpensive reducing agent with the ability to control the size of silver cations to nanoparticles[30-32]. The placement of silver nanoparticles inside the PIL structure and their integration together give the nanocomposite structure certain characteristics that are listed below:

1) the add new interaction between silver nanoparticle and drug ( $\pi$-cation, electrostatic interaction, coordination reaction and hydrogen bond) 2) the increase of the hydrophilic property of carrier owing to existence of hydroxyl groups in the mesoporous framework to help to high and appropriate dispersity of carrier in SBF 3) the covalently bonded ionic groups that make the compound steady under various situation, chiefly high temperature, moisture and acidic environment and different $\mathrm{pH} 4$ ) low using of II in structure that is economical owing to their cost 5) fabrication of Ag NPs without aggregation owing to anchor of nanoparticle in the pores of the mesoporous framework for the stabilization of Ag NPs.[33-36] 


\subsection{Characterization of PILP-Ag organic-inorganic nanocomposite}

The structure of a) PILP-Ag organic-inorganic nanocomposite and was determined by FT-IR spectroscopy and the results are presented in Fig. 2. Peaks at 2853-3022 $\mathrm{cm}^{-1}$ are attributed to the $\mathrm{C}-\mathrm{H}$ bonds stretching vibration that were basic characteristic peaks of of the DVB-IM copolymer chain in structure. The peak at $1641 \mathrm{~cm}^{-1}$ is assigned to the bending mode of the -OH group of adsorbed water by hydrogen bonding and the broadband at $3437 \mathrm{~cm}^{-1}$ is due to the remaining hydroxyl groups on the Ag Nps. Furthermore, FT-IR spectrum of PILP-Ag organic-inorganic nanocomposite showed other absorption bonds at $1597-1698,713-903,1021-1223,1358$ and $1498 \mathrm{~cm}^{-1}$ that are corresponding to $\mathrm{C}=\mathrm{C}$ bond in the aromatic rings, unsaturated stretching of $\mathrm{C}-\mathrm{H}$, band of the $\mathrm{C}-\mathrm{N}$ linkage and alkyl stretching of the copolymer, respectively.

In the next step, to prove the successful synthesis, reduction and stabilization of Ag NPs into the voids of the mesoporous polymer, the structural properties were investigated by XRD (Fig. 3) in the range of $2 \theta=$ $10^{\circ}-70^{\circ}$ that presence of peaks at $2 \theta=38.34,44.35$ and 64.57 can be ascribed to 111,200 and 220 . In addition, the broad XRD peak at a low diffraction angle of $15^{\circ}$ to $30^{\circ}$ corresponds to the amorphous-state PILP substrate[37].

The SEM image (Fig. 4) of PILP-Ag organic-inorganic nanocomposite shows the nanocomposites have a homogeneous structure.

The nitrogen adsorption-desorption and BJH pore size distributions results were exposed in Fig. 5. Nitrogen isotherm for synthesized-nanocarrier presented type IV curve with a hysteresis loop of type H1, confirming the presence of uniformity of mesopores[38]. The BET surface area, pore-volume and mean pore diameter of the PILP-Ag organic-inorganic nanocomposite are $548 \mathrm{~m}^{2} \mathrm{~g}^{-1}, 1.17 \mathrm{~cm}^{3} / \mathrm{g}$ and $2.38 \mathrm{~nm}$, respectively. The availability and abundance of uniform spaces, which are due to the high surface area and the appropriate size of pores, can improve the performance of the drug carrier.

Transmission electron microscopy (TEM) image of the PILP-Ag organic-inorganic nanocomposite indicated that silver nanoparticles are formed and adequately distributed through the polymer lattice. (Fig. 6) and the corresponding particles size distributions of the prepared PILP-Ag organic-inorganic nanocomposite with the $0.8-1.4 \mathrm{~nm}$ average diameter. This really protects the PILP from the destruction and leaching of silver NPs throughout the different environments.

\subsection{Antibacterial activity of PILP-Ag organic-inorganic nanocomposite}

PILP-Ag organic-inorganic nanocomposite were evaluated for antimicrobial activity (Fig. 7). The bacteria selected in this research are classified as pathogenic super bacteria and can be used as appropriate candidates in antibacterial tests. The MIC of PILP-Ag organic-inorganic nanocomposite against 
Streptococcus aureus ATCC 35668 and Escherichia coli 0157 PTCC 1276 were establish to be 2-1024 and $2-1024 \mu \mathrm{g} / \mathrm{mL}$, respectively. The MBC of PILP-Ag organic-inorganic nanocomposite against the bacteria were found in the range of 2-2048 and 2-2048 $\mu \mathrm{g} / \mathrm{mL}$, respectively. The lowest concentration of PILP-Ag organic-inorganic nanocomposite for MIC test for E. coli. and S. aureus were $256,256 \mu \mathrm{g} / \mathrm{mL}$ and also, MBC test for E. coli. and S. aureus were $256,512 \mu \mathrm{g} / \mathrm{mL}$, respectively, these results show that PILP-Ag organic-inorganic nanocomposite could prevent growth and kill all tested bacterial pathogens. The antibacterial mechanism of the formed nanostructure mainly can be involves the electrostatic interactions of cationic and metallic parts (imidazolium units and silver NPs) with the negatively charged bacterial membrane[39, 40]. However, the hydrophobic part of the nanostructure (PILP) also plays a role in the mechanism and affects the internal and hydrophobic regions of the bacteria that this helps to rupture the cell membrane[41].

\subsection{Cytotoxicity analysis of PILP-Ag organic-inorganic nanocomposite}

MTT assay showed that PILP-Ag organic-inorganic nanocomposite with a concentration of $0.001 \mathrm{~g}$ and $0.005 \mathrm{~g}$ had a less damage on HFF-2 cells, because more than $90 \%$ of the treated cells were alive compared to the control group (Fig. 8). Furthermore, there is no significant difference in terms of cell growth and viability between concentrations of $0.001 \mathrm{~g}$ and $0.005 \mathrm{~g}$ of PILP-Ag organic-inorganic nanocomposite.

However, with increasing the concentration of nanomaterials, cells viability in cells treated was decreased about $25 \%$ and $45 \%$ with high concentrations of $0.01 \mathrm{~g}$ and $0.05 \mathrm{~g}$ of PILP-Ag organic-inorganic nanocomposite.

\subsection{Drug release behavior}

The drug release shows the amount of mass transfer from a solid phase to a broth phase under usual conditions. The principal phase in delivery of drug is the interaction between the nanocarrier of the drug and the buffer solution, which occurs between the carrier and buffer. Hence, kinetics of the drug release are related to the rate of the reaction at the inter-face, the rate of the flow of PBS solution on the path into the inter-face of PBS solution and carrier and the molecular diffusion of the dissolved drug molecules from the inter-face toward the broth solution. Consequently, the MTX release of PILP-Ag organic-inorganic nanocomposite was evaluated at $37^{\circ} \mathrm{C}$ and $\mathrm{pH} 7.4$ shown in Fig. 9. The drugs were released from PILP-Ag organic-inorganic nanocomposite by exchanging with phosphate anions and capillary forced release from structure at the desired $\mathrm{pH}$ in a stable method. In the first $20 \mathrm{~h}$, the most drug releasing levels were regarded to drugs absorbed in the surface of the PILP-Ag organic-inorganic nanocomposite and drugs, which were bonded to the substrate by, $\pi$-cation, hydrogen bonds and electrostatic interaction, quickly developing a therapeutic dose. After that, the available and remaining drugs balanced with PILP counter ions and coupling with Ag NPs, in addition to slowing down the release rate, reduce the release rate of the drug and deliver the drug continuously and for a longer constant period. Gradually the release increased 
and reached its maximum value (96.18\%) in 120 hours of release. The slow release rate allows the drug to reach the body over a longer period, thus reducing the number of doses the patient can take.

\section{Conclusion}

In this study, at the first, PILP was synthesized by radical polymerization and next, silver nanoparticles was anchored into PIL voids by in-situ reduction, and in the meantime enrich the adsorption capability of drug and antimicrobial effect of the nanocarrier and used as a new drug nanocarrier. The antimicrobial activity of several important pathogenic bacteria was tested. Furthermore, PILP-Ag organic-inorganic nanocomposite cytotoxicity was examined on HFF-2 Fibroblast Cells via MTT assay analysis. The results showed that the synthesized nanocomposite in physiological concentration has extremely low cytotoxicity against HFF cells in vitro and can be used as a suitable nanocarrier for drug delivery in the body. MTX was selected as the model drugs, being intercalated PILP-Ag organic-inorganic nanocomposite. The synthesized nanocarrier was characterized using SEM, FT-IR, XRD, TEM and BET to exhibit morphology and chemical structure. The PILP-Ag organic-inorganic nanocomposite was tested for the controlled release of MTX with in vitro method (PBS, and at $37^{\circ} \mathrm{C}$ in $\mathrm{pH}$ 7.4). The PILP-Ag organicinorganic nanocomposite will be able to have an applicable usage as different drug carriers.

\section{Declarations}

\section{Ethics approval and consent to participate}

The study was approved by Ethics Committee of Tabriz University of Medical Sciences, Tabriz, Iran.

\section{Consent for publication}

Not applicable

\section{Availability of data and materials}

All data used to generate these results is available in the main text.

\section{Competing interests}

The authors declare that they have no competing interests

\section{Funding}

This work was supported by Tabriz University of Medical Sciences, Tabriz, Iran.

\section{Authors' contributions}

$E A, V Y$ and MM designed the study and performed the vitro experiments; EA and RE carried out the biological experiments, all authors supervised the whole work and wrote the manuscript. All authors read 
and approved the final manuscript.

\section{Acknowledgements}

This study was supported by the Drug Applied Research Center, Tabriz University of Medical Sciences, Tabriz, Iran, Department of Radiation Oncology, Shahid Madani Hospital, Tabriz University of Medical Science, Tabriz, Iran and Molecular Medicine Research Center, Biomedicine Institute, Tabriz University of Medical Sciences, Tabriz, Iran.

\section{References}

1. M.C. Perry, The chemotherapy source book (Lippincott Williams \& Wilkins, 2008)

2. J.K. Saggar, I.F. Tannock, Int. J. Cancer Res. 134, 2726-2734 (2014)

3. N. Hasegawa, T. Nishimura, S. Ohtani, K. Takeshita, K. Fukunaga, S. Tasaka, T. Urano, K. Ishii, M. Miyairi, A. Ishizaka, Chest 136, 1569-1575 (2009)

4. C.-Y. Zhao, R. Cheng, Z. Yang, Z.-M. Tian, Molecules 23, 826 (2018)

5. M. Coccia, L. Wang, Technol. Forecast. Soc. Change 94, 155-169 (2015)

6. Z. Gao, L. Zhang, Y. Sun, J. Control. Release 162, 45-55 (2012)

7. R. Li, Z. Chen, Z. Dai, Y. Yu, Cancer Biol. Med. 18, 388 (2021)

8. A. Pandey, A.N. Nikam, G. Fernandes, S. Kulkarni, B.S. Padya, R. Prassl, S. Das, A. Joseph, P.K. Deshmukh, P.O. Patil, Nanomaterials 11, 13 (2021)

9. F. Coccolini, E. Cotte, O. Glehen, M. Lotti, E. Poiasina, F. Catena, Y. Yonemura, L. Ansaloni, Eur. J. Surg. Oncol. 40, 12-26 (2014)

10. R. Zhao, X. Liu, X. Yang, B. Jin, C. Shao, W. Kang, R. Tang, Adv. Mat. 30, 1801304 (2018)

11. T. Adak, J. Kumar, N. Shakil, S. Walia, J. Environ. Sci. Health B 47, 217-225 (2012)

12. S. Saeedi, S. Murjan, M.R. Nabid, J. drug del. sci. tech. 62, 102391 (2021)

13. X. Li, M. Sambi, A. DeCarlo, S.V. Burov, R. Akasov, E. Markvicheva, C. Malardier-Jugroot, M.R. Szewczuk, Nanomaterials 8, 588 (2018)

14. O. Mashinchian, R. Salehi, G. Dehghan, A. Aganejad, S. Davaran, Y. Omidi, J. Environ. Sci. Health A 47, 1701-1712 (2012)

15. R. Huang, Synthesis and characterization of tetraphenylethylene based amphiphilic copolymer as novel drug carrier, (2021)

16. M.L. Knox, M.W. Schuppel, Nano-Polymeric Biomaterials Used in Cancer Drug Delivery, (2021)

17. Q. Hu, Y. Lu, Y. Luo, Carbohydr. Polym. 17999 (2021)

18. O. Green, S. Grubjesic, S. Lee, M.A. Firestone, Polym Rev. 49, 339-360 (2009)

19. D. Mecerreyes, Prog. Polym. Sci. 36, 1629-1648 (2011)

20. M.M. Abolghasemi, B. Karimi, V. Yousefi, H. Behzadnia, H. Barzegar, M. Piryaei, New J. Chem. 39, 6085-6091 (2015) 
21. D. Mecerreyes, Applications of ionic liquids in polymer science and technology (Springer, 2015)

22. S. Mahalingam, A. Nugroho, D. Floresyona, K.S. Lau, A. Manap, C.H. Chia, N. Afandi, Int. J. Energy Res. In press

23. D.J. Siegel, G.I. Anderson, L.M. Paul, P.J. Seibert, P.C. Hillesheim, Y. Sheng, M. Zeller, A. Taubert, P. Werner, C. Balischewski, ACS Appl. Bio Mater. In press (2021)

24. J. Guo, Y. Qian, B. Sun, Z. Sun, Z. Chen, H. Mao, B. Wang, F. Yan, ACS Appl. Bio Mater. 2, 4418-4426 (2019)

25. Y. Yang, Z. Cai, Z. Huang, X. Tang, X. Zhang, Polym. J. 50, 33-44 (2018)

26. L. Timofeeva, N. Kleshcheva, Appl. Microbiol. Biotechnol. 89, 475-492 (2011)

27. E. Mansouri, V. Tarhriz, V. Yousefi, A. Dilmaghani, Adsorption 26, 1-8 (2020)

28. Y. Xue, Y. Guan, A. Zheng, H. Wang, H. Xiao, J. Biomater. Sci. Polym. Ed. 23, 1115-1128 (2012)

29. J.A. Jacob, S. Kapoor, N. Biswas, T. Mukherjee, C. Surf, A Physicochem Eng Asp 301, 329-334 (2007)

30. S. Zeroual, P. Estellé, D. Cabaleiro, B. Vigolo, M. Emo, W. Halim, S. Ouaskit, J. Mol. Liq. 310, 113229 (2020)

31. T.T. Tung, M. Castro, T.Y. Kim, K.S. Suh, J.-F. Feller, Anal. Bioanal. Chem. 406, 3995-4004 (2014)

32. Y. Wang, R. Cai, C. Chen, Acc. Chem. Res. 52, 1507-1518 (2019)

33. J. Zhang, L. Xiang, B. Yan, H. Zeng, J. Am. Chem. Soc. 142, 1710-1714 (2020)

34. M.M. Abolghasemi, V. Yousefi, E. Rafiee, Microchim. Acta 181, 1807-1814 (2014)

35. K.P. Charan, N. Pothanagandhi, K. Vijayakrishna, A. Sivaramakrishna, D. Mecerreyes, Eur. Polym. J. $60,114-122(2014)$

36. L. Xiong, X. Huang, Y. Liu, L. Pan, Sci. Eng. Compos. 24, 423-427 (2017)

37. A. Svidrytski, D. Hlushkou, M. Thommes, P.A. Monson, U. Tallarek, J. Phys. Chem. C 124, $21646-$ 21655 (2020)

38. Y. Huang, Q. Feng, Q. Yan, X. Hao, Y. Chen, Mini-Rev. Med. Chem. 15, 73-81 (2015)

39. Q. Xu, Z. Zheng, B. Wang, H. Mao, F. Yan, ACS Appl. Mater. Interfaces 9, 14656-14664 (2017)

40. V. Yousefi, V. Tarhriz, S. Eyvazi, A. Dilmaghani, J. Nanobiotechnology 18, 1-11 (2020)

\section{Figures}



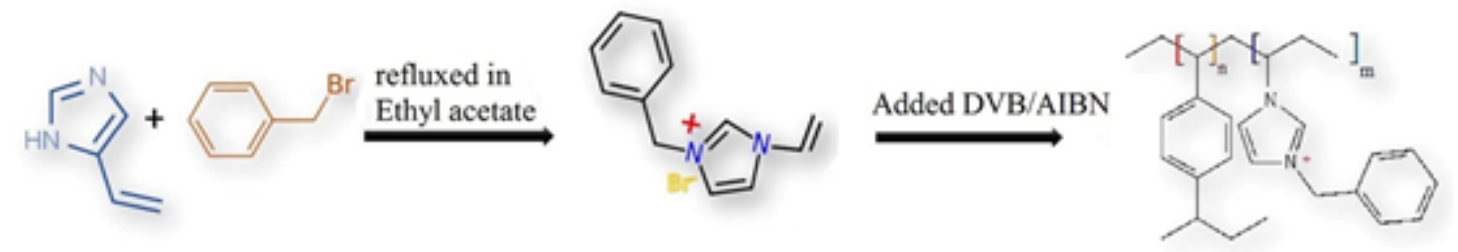

\section{ILVI-Br}

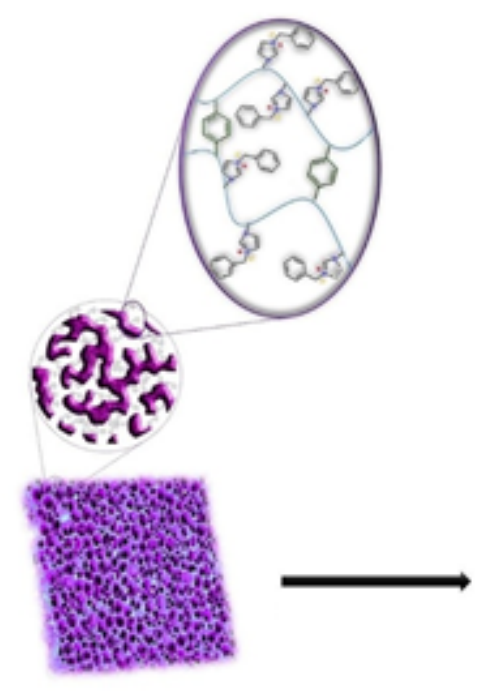

PILP

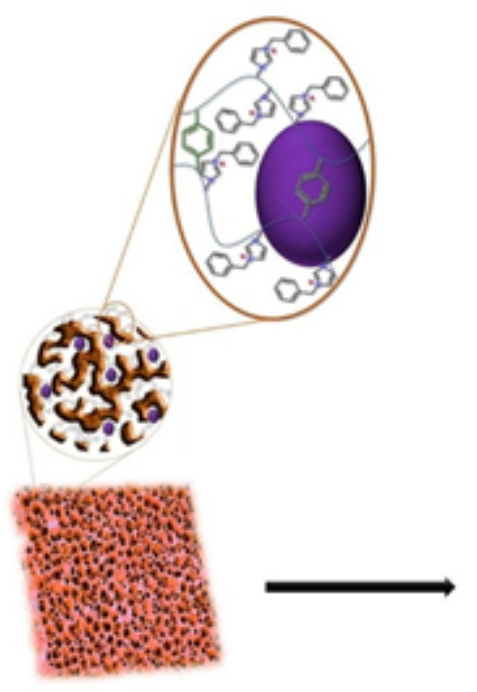

PILP-Ag

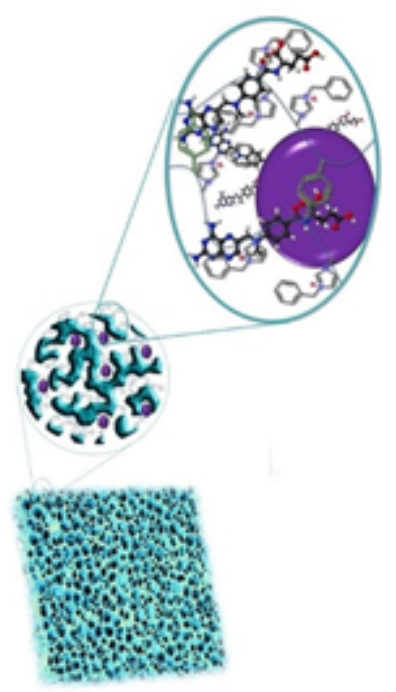

PILP-Ag/MTX

Figure 1

Schematic representation of preparation of PILP-Ag/MTX organic-inorganic nanocomposite. 


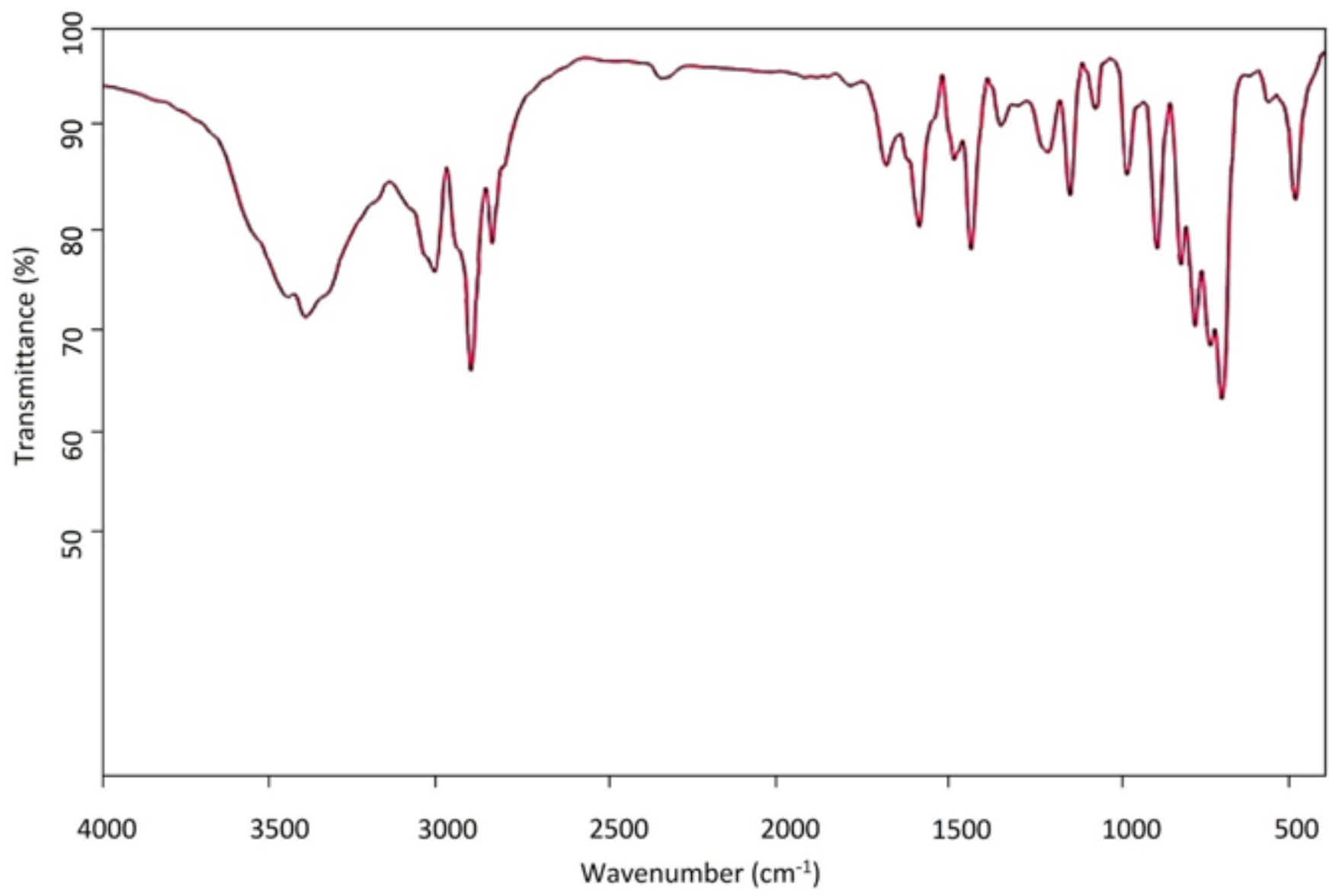

Figure 2

FT-IR spectrum of PILP-Ag/MTX organic-inorganic nanocomposite. 


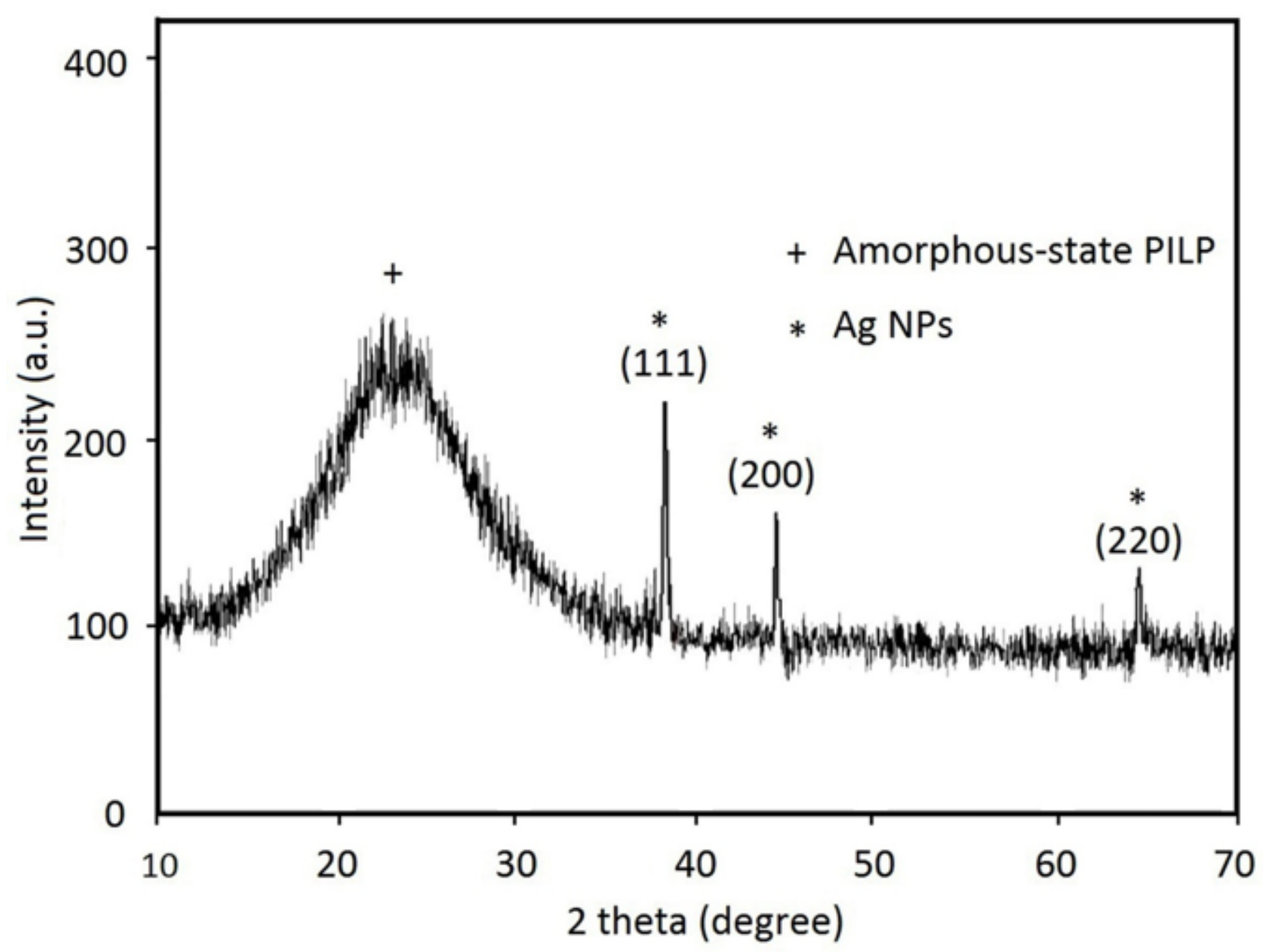

Figure 3

The XRD patterns of PILP-Ag/MTX organic-inorganic nanocomposite. 


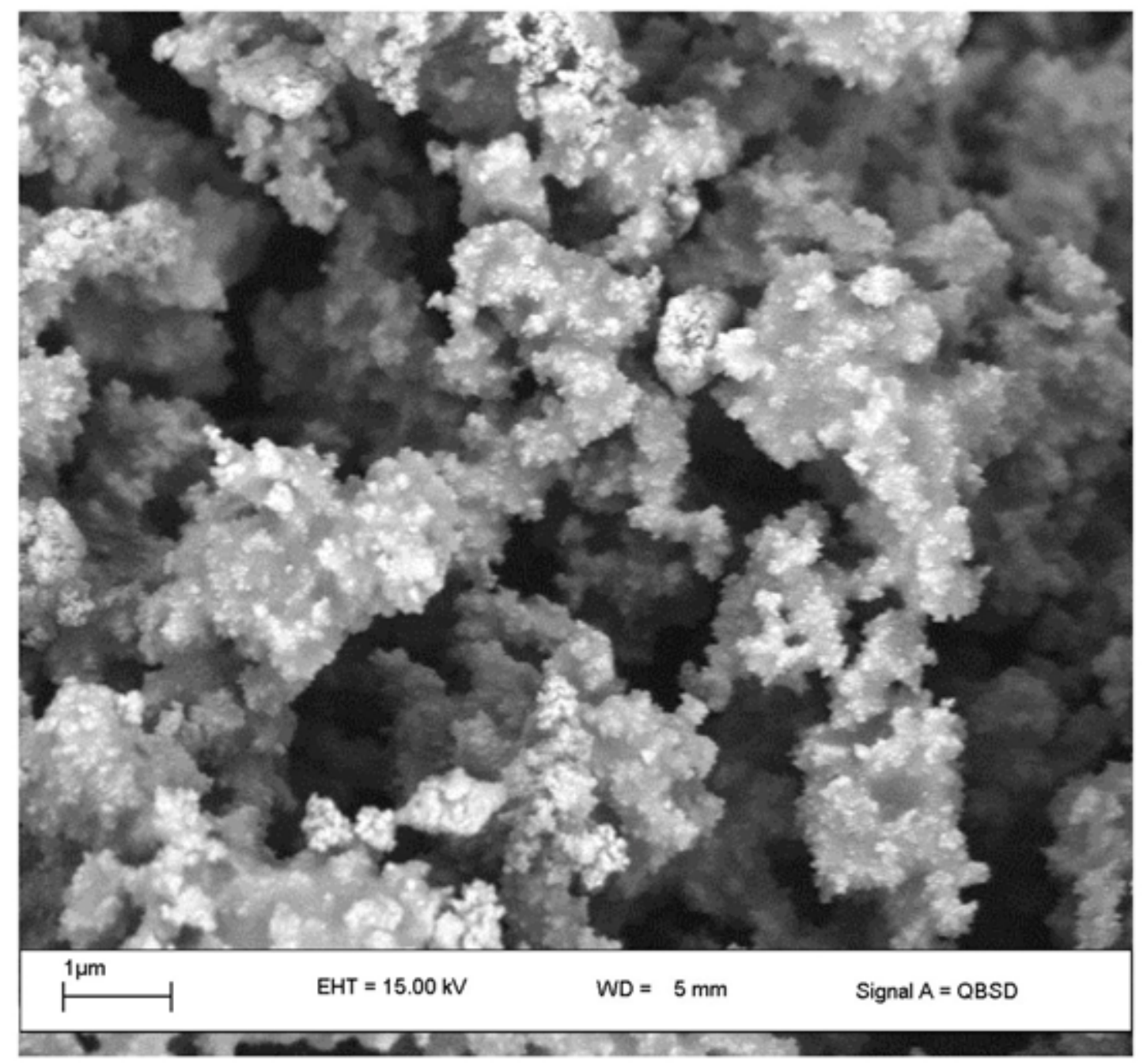

Figure 4

The SEM images of PILP-Ag/MTX organic-inorganic nanocomposite. 

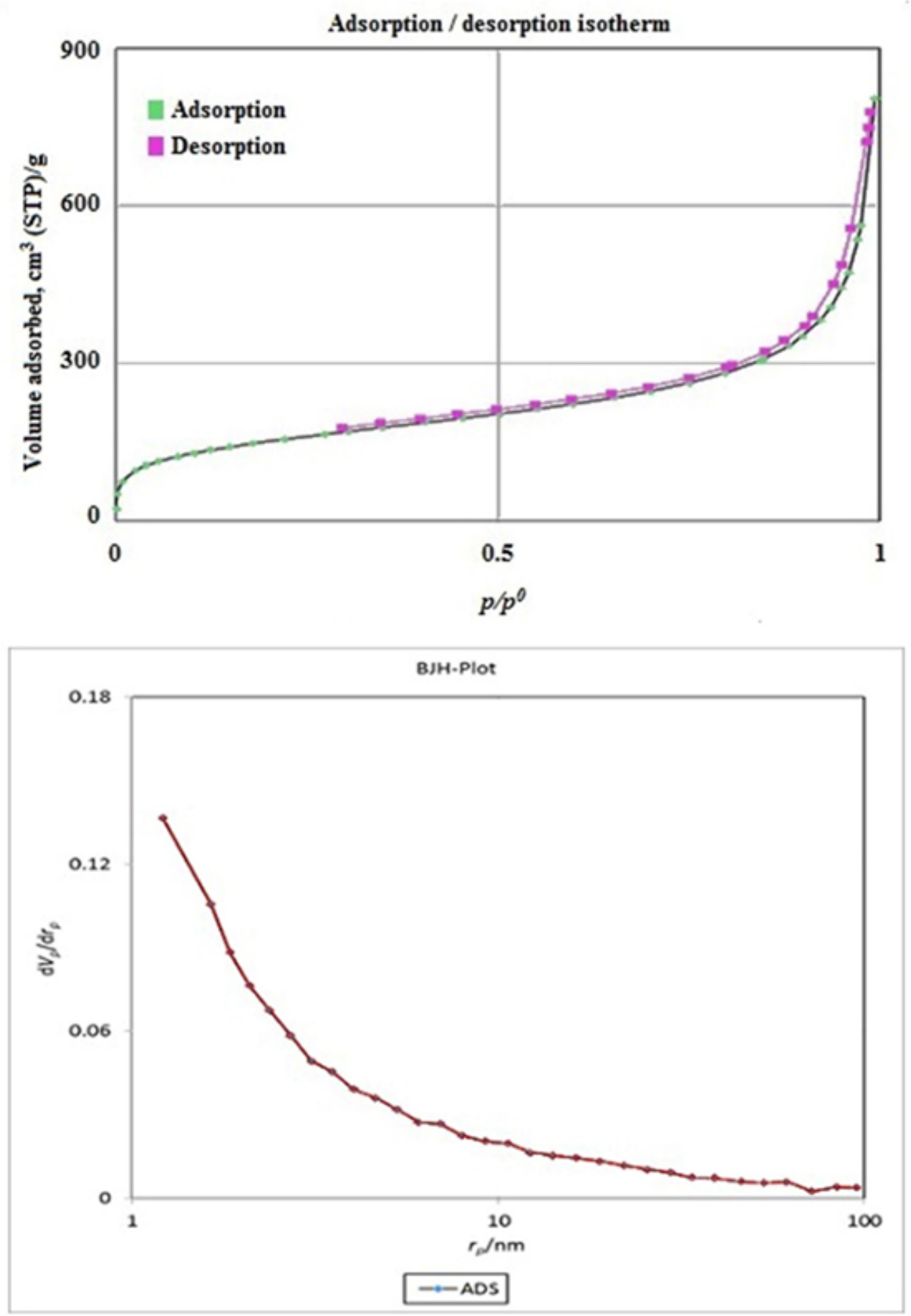

Figure 5

The nitrogen adsorption-desorption and BJH pore size of PILP-Ag/MTX organic-inorganic nanocomposite. 


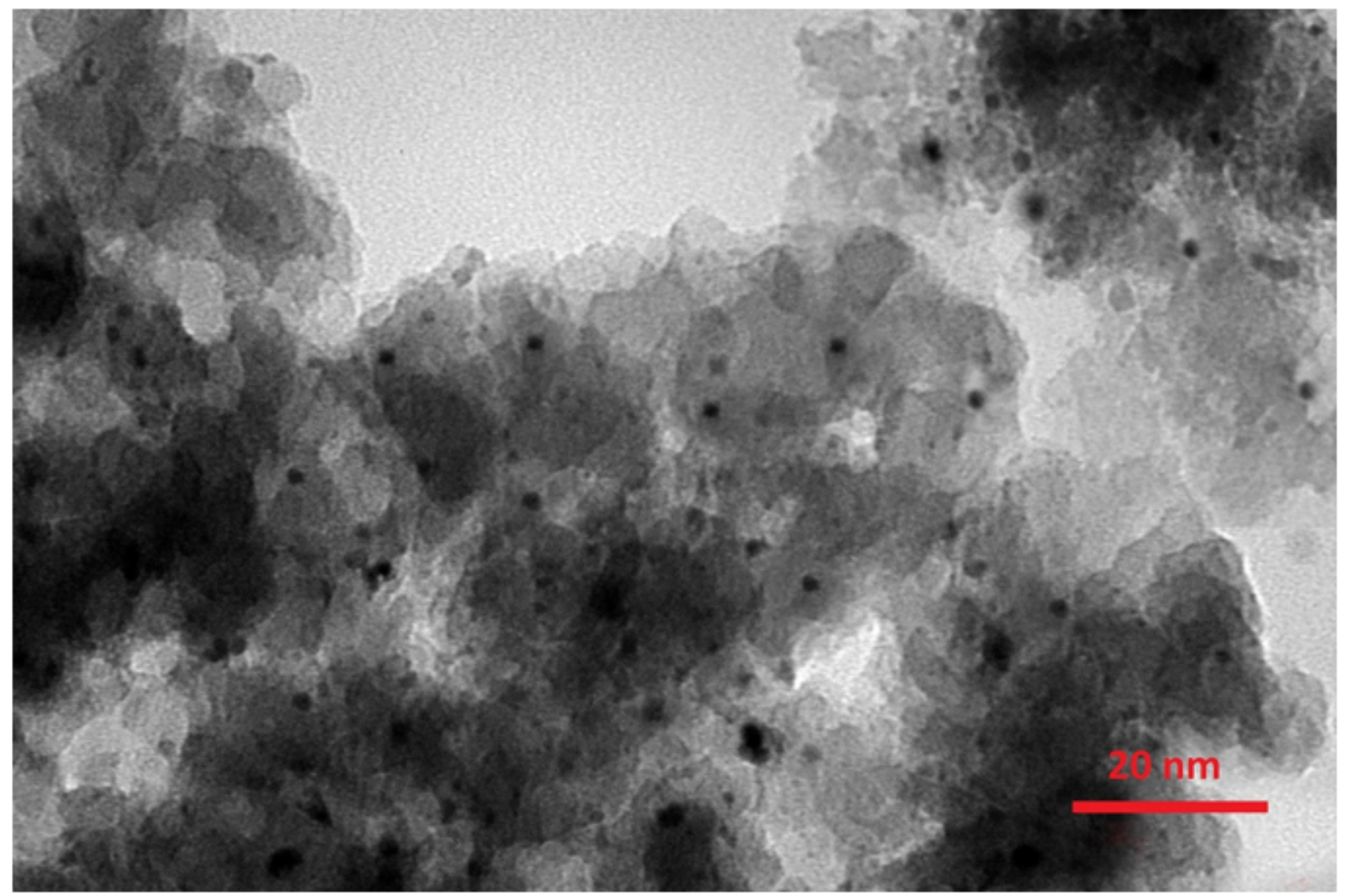

Figure 6

TEM image of the PILP-Ag organic-inorganic nanocomposite.

\begin{tabular}{|c|c|c|c|}
\hline Bacteria & Sources & MIC $(\mu \mathrm{g} / \mathbf{m l})$ & MBC $(\boldsymbol{\mu g} / \mathbf{m l})$ \\
\hline $\begin{array}{c}\text { Escherichia coli } \\
\text { O157 PTCC 1276 }\end{array}$ & $\begin{array}{c}\text { Human } \\
\text { gastrointestinal tract }\end{array}$ & 256 & 256 \\
\hline $\begin{array}{c}\text { Streptococcus } \\
\text { aureus ATCC } \\
\text { 35668 }\end{array}$ & Clinical isolate & 256 & 512 \\
\hline $\begin{array}{c}\text { Range of } \\
\text { MIC/MBC }\end{array}$ & & $2-1024$ & $2-2048$ \\
\hline
\end{tabular}


Figure 7

MIC and MBC ranges for E. coli. and S. aureus strains.

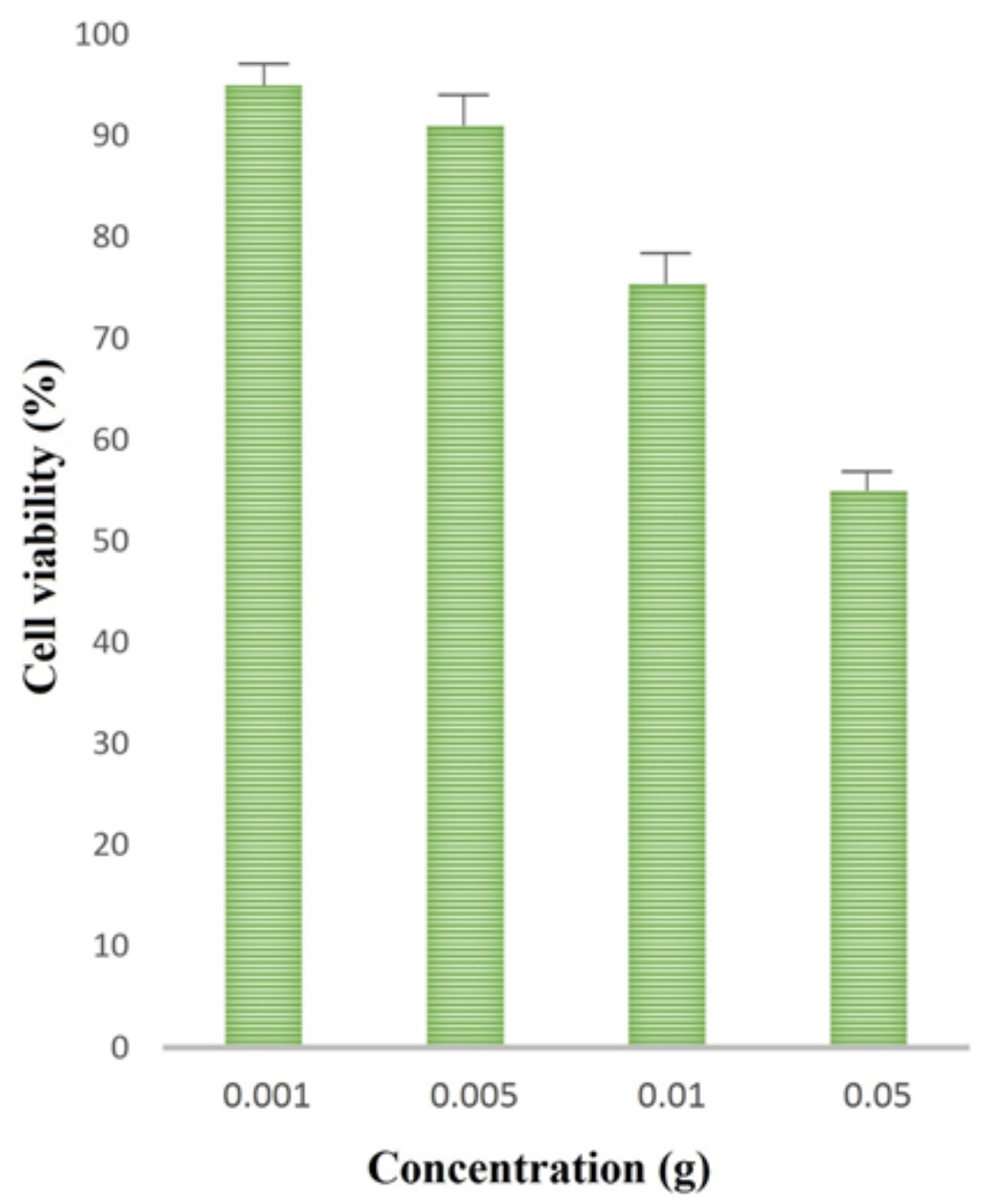

Figure 8

The result of MTT assay in $0.001,0.005,0.01$ and $0.02 \mathrm{~g}$ of PILP-Ag organic-inorganic nanocomposite. 


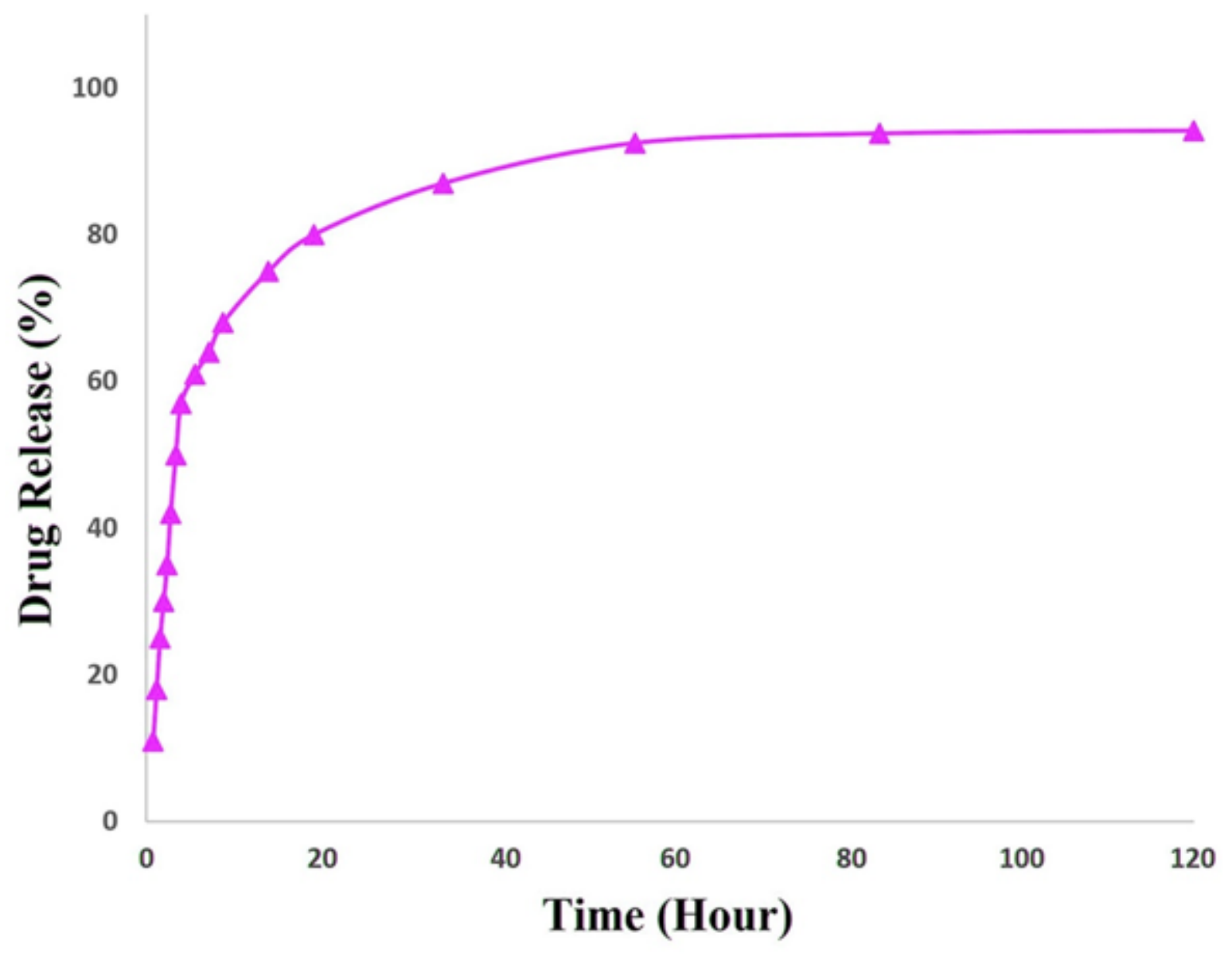

Figure 9

MTX release of PILP-Ag organic-inorganic nanocomposite was evaluated at $37^{\circ} \mathrm{C}$ and $\mathrm{pH} 7.4$. 